\title{
A EducaÇÃo Física nOS Institutos Federais: DIAGNÓSTICO ACERCA DOS REFERENCIAIS CURRICULARES, CONTEÚDOS E ABORDAGENS METODOLÓGICAS ${ }^{1}$
}

\author{
PHYSICAL EDUCATION IN FEDERAL INSTITUTES: DIAGNOSIS ABOUT \\ CURRICULAR REFERENCES, CONTENTS AND METHODOLOGICAL \\ APPROACHES
}

DOI: 10.23926/RPD.2526-2149.2020.v5.n3.p1627-1645.id845

\section{Juliano Daniel \\ Boscatto \\ Doutor em Desenvolvimento \\ Humano e Tecnologias \\ (UNESP) \\ Professor do IFSC \\ juliano.boscatto@ifsc.edu.br}

\section{Ivan Carlos Bagnara \\ Doutor em Educação nas \\ Ciências (UNIJUÍ) \\ Professor do IFRS \\ ivan.bagnara@erechim.ifrs.ed u.br}

\section{Luciano de Almeida}

Doutor em Educação nas

Ciências (UNIJUÍ)

Professor do IFFAR

luciano.almeida@iffarroupilha .edu.br

\section{Affonso Manoel Righi \\ Lang \\ Doutorando em Educação nas \\ Ciências (UNIJUI) \\ Professor do IFRS \\ affonso.lang@gmail.com}

\section{Fabrício Döring \\ Martins}

Doutorando em Ciências do

Movimento Humano

(UFRGS)

Professor do IFFAR

fabricio.martins@iffarroupilha .edu.br
Resumo: Este estudo tem o objetivo de compreender como acontece o desenvolvimento das ações didático-pedagógicas da Educação Física Escolar (EFE) no âmbito da Educação Profissional e Tecnológica (EPT), a fim de identificar quais os conteúdos ensinados (práticas corporais) e quais os referenciais curriculares utilizados pelos professores como base para o desenvolvimento do processo educativo no Ensino Médio Integrado (EMI). Foi desenvolvida uma pesquisa de abordagem qualitativa, na perspectiva descritiva de levantamento, da qual participaram cento e vinte docentes dos Institutos Federais (IFs) das cinco regiões do país. O desenvolvimento do estudo permitiu identificar e problematizar os referenciais curriculares/teóricos utilizados pelos docentes, os conteúdos ensinados e as abordagens metodológicas. Ao realizar uma espécie de triangulação entre as três perspectivas, percebe-se um alargamento do currículo da EFE nos IFs, indicando haver, nesse contexto, movimentos em prol do desenvolvimento da EF sob o prisma de um componente curricular, produzindo conhecimentos e saberes multidimensionais.

Palavras-chave: Ensino de Educação Física. Ações DidáticoPedagógicas. Institutos Federais.

\begin{abstract}
This study aims to understand how the development of didactic-pedagogical actions of School Physical Education (SPE) takes place within the scope of Professional and Technological Education (PTE), in order to identify which contents are taught (body practices) and which are the references curricula used by teachers as a basis for the development of the educational process in Integrated High School (IHS). Qualitative research was developed from the narrative perspective of the survey. In order to tackle this proposal, one hundred and twenty professors from the Federal Institutes (FIs) from the five regions of the country participated. The study's development allowed the identification and problematization of the curriculum frameworks in a curricular and theoretical way, the contents taught, and the methodological approaches. When performing a kind of triangulation among the three perspectives, it is noticed an extension of the SPE curriculum in the FIs, indicating that, in this context, there are movements in favor of the development of PE under the prism of a curricular component, producing multidimensional knowledge.
\end{abstract}

Keywords: Physical Education Teaching. Didactic-Pedagogical Actions. Federal Institutes.

1 Estudo realizado pelo Grupo de Estudos e Pesquisa em Educação Física dos/nos Institutos Federais (GEPEFIF). 


\section{INTRODUÇÃO}

A problemática inerente à organização curricular e ao desenvolvimento dos processos educativos são temas recorrentes em discussões contemporâneas na educação escolar e nos componentes do currículo, nos mais variados níveis de ensino e modalidades educativas. Assim, a Educação Física Escolar (EFE), na condição de componente curricular obrigatório da Educação Básica, articulado com a proposta pedagógica da escola, de acordo com a Lei de Diretrizes e Bases da Educação Nacional n 9394/96 (BRASIL, 2017) e com diversos autores da área (KUNZ, 2004; GONZÁLEZ; FENSTERSEIFER, 2009; 2010; GONZÁLEZ; FRAGA, 2012; BRACHT et. al, 2014; BAGNARA, FENSTERSEIFER, 2019; BRACHT, 2019), necessita dar conta de uma série de "novos" elementos para atender ao seu novo status na educação escolar. Nessa conjuntura, aos professores de EFE apresenta-se o desafio de avançar na produção de conhecimentos e saberes acerca das práticas corporais, "abandonando" a abordagem de outrora, vinculada, exclusivamente, à atividade corporal, ao "exercitar-se" e à prática esportiva (com um fim em si mesma).

No que concerne à Educação Física $(E F)$ inserida na Educação Profissional e Tecnológica (EPT), especificamente no Ensino Médio Integrado (EMI), não é diferente. Pelo contrário, nesse contexto educativo, parece que a quantidade de problemáticas e desafios demandados aos professores avolumam-se, pois, ao desafio de produzir conhecimentos acerca das práticas corporais, soma-se a necessidade de pensar o ensino da EF articulada com a EPT e com os demais componentes do currículo, tanto do núcleo propedêutico/comum, quanto do núcleo técnico-profissional, conforme apontado por Almeida e Martins (2020).

No entanto, para avançar com a elaboração de propostas ou soluções (mesmo provisórias) para esse desafio em toda a sua magnitude e complexidade, o professor de EF necessita elaborar respostas para perguntas fundamentais. Nessa conjuntura, aspectos que podem ser considerados básicos e específicos, como, por exemplo, “o que ensinar" e "como ensinar" nas aulas de EF no EMI, podem ser considerados centrais nesta perspectiva. Ao problematizar tais aspectos, emergem algumas questões que norteiam o desenvolvimento deste estudo: quais referenciais curriculares os professores de EF que atuam com docência no EMI a EPT utilizam para embasar sua proposta de trabalho ou, em outros termos, para desenvolver o seu planejamento de ensino? Quais conteúdos são ensinados nas aulas de EF (o que ensinam?) e quais perspectivas metodológicas ou quais abordagens utilizam (como ensinam?)?

Entendemos que melhor compreender a dinâmica desse movimento na EFE, nesta modalidade educativa e nível de ensino, pode oportunizar/possibilitar a realização de um 
fundamental exercício crítico-reflexivo. Esse movimento, por sua vez, possui potencial para auxiliar os professores na compreensão das responsabilidades educativas da EF na EPT e, além disso, pode fornecer "pistas" interessantes para avançar na empreitada de propor articulações/integrações curriculares com os demais componentes do núcleo propedêutico e do núcleo técnico-profissional.

Atentar para essa questão, tem importância considerável, pois, de acordo com Silva, Silva e Molina Neto (2016), se não tivermos posições claras sobre o conhecimento e a ação pedagógica da EF (neste caso, na EPT integrada ao Ensino Médio) e se não soubermos "o que" e "como" ensinar nas aulas de EF, correremos o risco de nos deparar com aqueles que nos dirão o que fazer. Assim, este estudo possui como objetivo compreender como acontece o desenvolvimento das ações didático-pedagógicas da EFE no âmbito da EPT relativamente aos referenciais curriculares, aos conteúdos de ensino e às abordagens metodológicas utilizadas pelos professores para o desenvolvimento do processo educativo no EMI.

\section{Procedimentos Metodológicos}

Este estudo caracteriza-se como um trabalho de natureza qualitativa do tipo descritivo, tendo em vista o objetivo de compreender como os professores de EF vêm desenvolvendo os processos de ensinar e aprender no EMI. Do ponto de vista de seus procedimentos técnicos, é uma forma de pesquisa de levantamento, pois envolve respostas diretas dos docentes através de questionário (SILVA; MENEZES, 2001). A pesquisa contou com a colaboração de cento e vinte professores de EF situados em IFs em todo o Brasil. Na análise e discussão dos resultados, denominamos os professores a partir da localização geográfica em que atuam, por exemplo, o "professor IF Norte" é docente de um IF que está localizado nessa região. O Quadro 1 demonstra a localização da amostra do estudo.

Quadro 1 - Número de docentes participantes por região dos
\begin{tabular}{|c|c|}
\hline Região & Número de colaboradores \\
\hline Norte & 14 \\
\hline Nordeste & 25 \\
\hline Centro-oeste & 19 \\
\hline Sudeste & 26 \\
\hline Sul & 36 \\
\hline Total & $\mathbf{1 2 0}$ \\
\hline
\end{tabular}

Fonte: elaboração dos autores, 2020. 
O Quadro 2, demonstra a caracterização dos participantes quanto a sua formação acadêmica:

Quadro 2 - formação acadêmica dos docentes

\begin{tabular}{|l|c|c|}
\hline Formação inicial em nível de graduação & $\mathbf{N}$ & $\mathbf{\%}$ \\
\hline Licenciatura em EF & 41 & 34,2 \\
\hline Bacharelado e Licenciatura em EF & 50 & 41,7 \\
\hline Bacharelado em EF & 1 & 0,8 \\
\hline Licenciatura Plena em EF & 26 & 21,7 \\
\hline Bacharelado e Licenciatura Plena em EF & 2 & 1,6 \\
\hline Total & $\mathbf{1 2 0}$ & $\mathbf{1 0 0}$ \\
\hline Formação em nível de pós-graduação & $\mathbf{N}$ & $\mathbf{\%}$ \\
\hline Não possui & 1 & 0,8 \\
\hline Especialização & 15 & 12,5 \\
\hline Mestrado & 69 & 57,5 \\
\hline Doutorado & 35 & 29,2 \\
\hline Total & $\mathbf{1 2 0}$ & $\mathbf{1 0 0}$ \\
\hline
\end{tabular}

Fonte: Elaboração dos autores, 2020.

Como instrumento de produção de dados foi utilizado um questionário online, via plataforma Google Forms, por proporcionar maior facilidade de participação na pesquisa, em menor tempo e em diferentes lugares. O questionário foi elaborado a partir de questões de múltipla escolha que buscaram identificar o perfil acadêmico e profissional dos participantes do estudo (dimensões pessoais, formação acadêmica, níveis de atuação, participação em projetos). Foi constituído, também, por questões abertas, que versavam sobre as especificidades dos processos de ensino dos professores, referenciais utilizados, conteúdos ensinados, perspectivas e abordagens metodológicas utilizadas em suas aulas.

Cabe destacar que nesse estudo, o foco de análise dá ênfase às questões relacionadas ao ensino, em especial, às que se referem à docência no $\mathrm{EMI}^{2}$. Os questionários foram enviados para as Reitorias de todas as regiões do país, CEFETs e Colégio Pedro II e para todos os campi dessas instituições. Algumas Reitorias e campi encaminharam os questionários aos seus docentes, outras nos encaminharam os endereços de $e$-mail dos docentes. Ainda, foi solicitado

2 A pesquisa faz parte de uma produção maior realizada por um grupo de estudos de professores de EF, que compartilham experiências de ensino, de pesquisa e de extensão em uma plataforma virtual que pode ser acessada em https://aedfnosifs.com.br/ a todos que queiram conhecer e socializar suas ações pedagógicas desenvolvidas no âmbito dos IFs. 
que os docentes enviassem o link do questionário aos seus pares via grupos de e-mail e grupos de redes sociais.

Ao acessar o formulário eletrônico, os docentes deveriam ler o Termo de Consentimento Livre e Esclarecido e assinalar a opção "concordo" ou "não concordo". Ao concordar, havia um direcionamento para o questionário e as questões eram apresentadas ao participante. $\mathrm{O}$ estudo seguiu todas as normas para pesquisas envolvendo a participação de seres humanos e foi aprovado pelo Comitê de Ética, com parecer consubstanciado de número 3.284.290.

Para a análise e interpretação dos dados produzidos, utilizamos a análise de conteúdo (BARDIN, 2011). A análise de conteúdo, conforme orientações da autora, foi organizada em pré-análise (organização), exploração do material (codificação e categorização), tratamento dos resultados obtidos e interpretação (informações fornecidas pela análise).

\section{ANÁLISE E DISCUSSÃo DOS RESULTADOS}

A partir das respostas dos docentes, emergiram três categorias para problematização e discussão: referências de base para os processos educativos; conteúdos ensinados; abordagens metodológicas para o desenvolvimento das aulas de EF. Apesar de haver interdependência entre as três categorias no desenvolvimento das aulas de EF e concepção dos projetos educativos, no contexto deste estudo, optamos por analisá-las num primeiro momento, separadamente, para, posteriormente ao final do texto, tecer elaborações e argumentos articulando-as.

\subsection{REFERENCIAIS DE BASE PARA OS PROCESSOS EDUCATIVOS}

Essa categoria tem como centralidade analisar os pressupostos teórico-epistemológicos da área que embasam o desenvolvimento da EF na EPT no EMI. Assim, foi possível visualizar as referências, documentos e diretrizes em que os professores de EF se apoiam para a organização, planejamento curricular e o desenvolvimento das práticas de ensino. Nesses termos, as respostas dos colaboradores do estudo indicaram, basicamente, três elementos: as Propostas Curriculares governamentais; os documentos e diretrizes curriculares do próprio IF em que os professores atuam e referências teóricas do campo da EF no Brasil (produções teóricas de professores, autores e pesquisadores).

No que concerne às propostas curriculares governamentais, os docentes indicam a utilização de documentos e diretrizes elaborados pelos órgãos do Estado. Tais respostas referendaram principalmente os seguintes documentos: a Base Nacional Comum Curricular (BNCC); os Parâmetros Curriculares Nacionais (PCNs) e as Propostas Curriculares elaboradas pelos estados da federação em que os docentes atuam. Tais dados demonstram que, conforme 
escreve Boscatto (2017), esses documentos estruturadores do currículo (conjunto de documentos e de materiais de caráter administrativos e pedagógicos) têm influência direta nas práticas de ensino dos professores pelo caráter propositivo e pragmático que possuem.

A versão final da BNCC para o Ensino Médio foi homologada recentemente (2017) e, ao analisarmos os dados produzidos, há evidências de que os professores já buscam essa referência para dar subsídios às suas ações docentes. A BNCC, em sua essência, vem apontar os conhecimentos mínimos, com as competências e as habilidades que os estudantes de diferentes instituições de ensino têm o direito de aprender durante a educação básica. Não diferente da BNCC, os PCNs (BRASIL, 1998), desde sua publicação, vêm servindo de base para a atuação docente. Várias edições foram sendo produzidas para os diferentes níveis de ensino a partir dessa data. Da mesma forma, as Propostas Curriculares de estados da federação vêm, há décadas, constituindo-se como um importante ponto de apoio ao trabalho pedagógico (BOSCATTO, 2017).

Os marcos legais educacionais podem ser considerados importantes aportes teóricos por possuírem como centralidade apresentar diretrizes gerais para auxiliar os professores no desenvolvimento dos processos educativos. Assim, podemos entender que o conteúdo da legislação educacional/marcos legais é importante, pois, conforme Bagnara (2017), tais documentos podem ser politicamente tensionados, mas não ignorados pelos professores, pois, dentre outras coisas, tratam-se de elaborações da República, aprovadas pelos representantes da população brasileira.

Os estudos de Gramorelli e Neira (2009), Barros e Darido (2009), Buogo e Lara (2011), Diniz e Darido (2015), Boscatto e Darido (2017) demonstram a influência que esses documentos estruturantes do currículo têm para as práticas de ensino da EF. De maneira geral, para os autores, esses documentos tornam-se importantes na medida em que podem proporcionar uma diversificação de conteúdos de ensino e, também, quanto às formas de abordagem dos conhecimentos de maneira que possibilite a aprendizagem de aspectos didáticos de caráter conceitual, procedimental e atitudinal.

Os professores também fazem destaque aos documentos balizadores do currículo que são formalizados por órgãos colegiados dos próprios IFs como, por exemplo, os Projetos Pedagógicos dos Cursos (PPCs). Esses documentos organizam as práticas educativas dos diferentes componentes curriculares para que fiquem alinhadas às características e às finalidades da própria instituição em que se atua, dando um aporte teórico e algumas diretrizes para a organização da tarefa educativa nas especificidades de cada campo de tematização. 
Atentar para os PPCs é algo fundamental, pois, além de aspectos que poderiam ser considerados da alçada administrativa e que poderiam se constituir em "obrigatoriedade" (SACRISTÁN, 2000), no âmbito de cada instituição, não se pode perder de vista que são os projetos de curso que sistematizam uma série de elementos determinantes para o processo formativo. Dentre tais elementos, podem ser destacados o perfil do egresso, os objetivos do curso e os objetivos e ementários de todas os componentes curriculares.

Assim, os PPCs podem constituir-se em importantes pontos de apoio para nortear o desenvolvimento do trabalho pedagógico, pois eles apresentam as diretrizes almejadas para determinado curso, em determinado contexto, para determinados estudantes e para todas os componentes da grade curricular. Em outros termos, os PPCs, que deveriam ser elaborados coletivamente, seguindo alguns determinantes legais, sistematizam o percurso que deve ser trilhado por professores e estudantes e, também por isso, se constituem em importante ponto de apoio ao trabalho pedagógico.

Além de documentos considerados legais e aprovados por instâncias governamentais e /ou institucionais, os professores indicaram que as bases teóricas do campo da EF, também são utilizadas como referência para organizar os processos educativos. Os professores mencionaram livros técnicos das ciências biológicas, bem como autores do campo da EFE como González, Kunz, Darido, Rufino, Daólio e, ainda, a obra Metodologia do Ensino da Educação Física, elaborada pelo grupo denominado "Coletivo de Autores" (2012).

Entendemos essa premissa como algo deveras importante, pois, em certa medida, esse dado permite, dentre outras coisas, perceber avanços no que concerne à ruptura com uma crítica que por anos esteve endereçada tanto aos professores de EF que atuam no contexto escolar, quanto aos professores que atuam na formação de professores, e, também, aos autores das mais variadas tendências pedagógicas. Embora o campo acadêmico-científico da EF esteja se desenvolvendo por diferentes vieses teórico-científicos, conforme afirmam Costa e Nascimento (2006) e Boscatto e Darido (2017), muitas vezes, as perspectivas dos autores e as tendências pedagógicas encontram algumas dificuldades em dialogar com questões mais pontuais relacionadas ao "chão da escola". Contudo, com base nas evidências desta pesquisa, em tese e pelo menos no contexto dos IFs, e mesmo que de forma incipiente, parece haver um movimento contrário, aproximando tais obras e tendências às ações dos professores.

Assim, no que concerne ao contexto deste estudo, parece-nos que os professores que atuam nos IFs têm procurado desenvolver seu trabalho educativo pautado, ao mesmo tempo, por documentos legais do Estado e documentos legais institucionais, o que possibilitaria o 
desenvolvimento de um processo educativo com maior proximidade ao almejado no âmbito da legislação. Além disso, entendemos que articular e tensionar os marcos legais com a produção teórica da área pode ser uma importante alternativa para que o professor possa enfrentar com seriedade os problemas e dificuldades que emergem no cotidiano escolar de tempos em tempos.

\subsection{Conteúdos EnSINAdos nas AUlas de EdUCAÇÃo Física}

Ao analisar os conteúdos que são ensinados nas aulas de EF nos IFs, e apontados no questionário, os professores citam uma variedade de possibilidades: esportes, jogos, ginásticas (demonstração; condicionamento físico; de conscientização corporal), lutas, práticas corporais de aventura e dança. Além dessas práticas corporais "mais comuns ou tradicionais" (que foram incorporadas pela EF enquanto campo de tematização), os docentes relatam que fazem parte de seus planejamentos de ensino conteúdos relacionados com as artes circenses, brincadeiras populares, esportes adaptados, jogos eletrônicos, práticas corporais alternativas com ênfase na problematização dos modismos, jogos de mesa e tabuleiro.

Com base nas respostas dos professores, pode-se presumir que a EF nos IFs, pelo menos do ponto de vista da diversidade de temas estudados, rompe com alguns paradigmas estabelecidos ao longo da história da área. Esse é um aspecto importante, pois a EF apresenta um histórico de conteúdos relacionados à promoção de saúde e ao esporte nos mais variados níveis de ensino, como demonstram as pesquisas de Resende (2009), Sampaio (2010), Bagnara (2013), Silva (2014), Boscatto e Darido (2017), dentre outros. Assim, há de se reconhecer os avanços que teoricamente foram apresentados pelos professores participantes deste estudo, permitindo vislumbrar, neste caso, uma $\mathrm{EF}$ mais conectada com a produção teórica contemporânea que a concebe como um componente curricular que possui responsabilidade de tematizar, no contexto educacional, o vasto universo das práticas corporais.

Além disso, ao relacionar os dados produzidos pela pesquisa com os referenciais curriculares utilizados pelos professores e os conteúdos ensinados, pode-se perceber que há coerência nas propostas didáticas. A maioria dos referenciais curriculares, publicados a partir do final da década de 90 do século passado, abordam unidades temáticas semelhantes entre eles e, também, semelhantes às temáticas referidas pelos participantes do estudo. Por exemplo, os PCNs (BRASIL, 1998) recomendam como unidades temáticas os jogos, esportes, danças, ginásticas e lutas. A BNCC (BRASIL, 2017) traz como unidades temáticas brincadeiras e jogos, esportes (e suas classificações), ginástica (e seus diferentes tipos), danças, lutas e práticas 
corporais de aventura. Outros referenciais estaduais abordam também, em grande medida, unidades temáticas iguais ou semelhantes (RIO GRANDE DO SUL, 2009; 2018; PERNAMBUCO, 2013; PARANÁ, 2018; MINAS GERAIS, 2019) indicando haver uma espécie de consenso na área acerca dos conteúdos que são objeto de estudo e ensino da EFE.

Apesar de entender a perspectiva posta como um avanço importante para a área, pode ser pertinente tecer argumentos em forma de contraponto ou que permitem melhor dimensionar essa questão. Nesse sentido, da mesma forma que Bagnara (2017), entendemos que tão importante quanto atentar para a diversidade de conteúdos que são ensinados nas aulas de $\mathrm{EF}$, é pensar a forma como tais conteúdos são ensinados e quais saberes e conhecimentos são produzidos. Relativamente a essa preocupação, o referido autor afirma que, muito mais (ou tão) preocupante do que somente "tratar de futebol" nas aulas de EF, é pensar na forma como o "futebol é tratado". Em outros termos, se o "futebol" ou tantos outros conteúdos da especificidade da EF forem tratados de forma reducionista, pode-se deixar "a exclusividade da crítica com o inimigo" (FENSTERSEIFER, 2013a, p. 51), fortalecendo a perspectiva histórica de prática esportiva ou corporal com um fim em si mesma, porém, agora, abarcando "uma variedade" maior de conteúdos.

Mesmo sendo pertinente essa preocupação, percebe-se que em vários IFs há o estudo de conteúdos que procuram atentar para uma espécie de alargamento ou ampliação de abordagens, vinculando-as, nesse sentido, com dimensões de conhecimentos que extrapolam o fazer corporal e articulam-se com perspectivas outras. As respostas dadas pelos docentes, quando questionados sobre o que ensinam nas aulas de $\mathrm{EF}$, fornecem alguns indicativos para maior e melhor reflexão acerca dessa prerrogativa. Assim, foi possível identificar que os docentes abordam temáticas que envolvem os conhecimentos sobre o corpo relacionados com a cultura, com a saúde, com a fisiologia/anatomia; tematizam atividade e exercício físico e sua relação com a saúde, com a dieta e com o balanço calórico; que tratam sobre a prevenção ao consumo de drogas lícitas e ilícitas; bem como a aspectos ligados aos estudos de gênero, violência, meio ambiente, dentre outros.

Desta forma, perante as inúmeras e variadas temáticas citadas pelos entrevistados, fica evidenciado que há avanços na questão da tematização dos conteúdos em perspectivas mais abrangentes da EF. Percebe-se, nesta conjuntura, que outros sentidos são atribuídos para as práticas corporais, para além de um "saber-fazer". Particularmente, consideramos esse "alargamento" do currículo e dos conteúdos importante, pois conforme afirmam Almeida e Fensterseifer (2018), a EFE necessita lidar com distintos saberes (corporais e conceituais), que, 
por um lado, não podem ser alcançados sem a experiência do se-movimentar humano, e por outro, não podem ser compreendidos se forem desconsiderados os conceitos. Assim, compreendemos que a relação dialógica entre o se-movimentar e os conceitos permite aos estudantes, conforme escrevem os autores, construir um entendimento complementar e compartilhado que se manifesta em diferentes formas de linguagem (verbais e não verbais) e que não podem (ou não deveriam) ser hierarquizados.

Ainda assim, não podemos deixar de considerar a quantidade elevada de respostas que referem preocupações com a saúde, principalmente sob o ponto de vista biológico, sugerindo, mesmo que indiretamente, haver uma relação linear (de exclusiva dependência) entre a prática de exercícios físicos e os níveis de saúde e qualidade de vida. Entendemos que essa é uma preocupação pertinente e fundamental, porém parece-nos apropriado melhor dimensioná-la. Para Bagnara e Fensterseifer (2019), a temática relacionada à saúde na EFE, justamente pela abrangência conceitual e pela influência que o contexto social exerce sobre ela, poderia ser tematizada tomando-a como um aspecto do debate sobre as práticas corporais e não como o elemento central da EF.

Assim sendo, da mesma forma que Bagnara e Fensterseifer (2019), defendemos a perspectiva de que a EF poderia, de forma gradativa e multidimensional, focar na tomada de consciência acerca da relação entre atividade física, exercício físico, saúde, qualidade de vida e contexto social. Desta forma, pode-se potencializar o desenvolvimento de um processo formativo pautado pela reflexividade e capacidade analítica multidimensional, pois a saúde e a qualidade de vida do sujeito dependem de muitos fatores (multifatorial), e apenas um deles está atrelado ao nível de atividade/exercício físico.

Ao encaminharmos as palavras finais deste tópico, no contexto deste estudo, mesmo que de maneira incipiente ou embrionária, pode-se perceber que há intencionalidade e preocupações em dar maior amplitude à perspectiva educativa da EF no EMI vinculado à EPT, para além do "tradicionalmente" desenvolvido na EFE ao longo de sua história. Entendemos que isso é fundamental quando se tem como premissa uma perspectiva formativa ampliada e abrangente, que atenda uma perspectiva mais ampla, como seria o caso do EMI (formação técnicoprofissional e formação humana). No entanto, para melhor compreender os processos educativos da EFE nos IFs, entendemos que é necessário avançar com o debate. Parece-nos que melhor dimensionar a forma como os professores abordam os conteúdos na especificidade desse componente curricular é um movimento que pode contribuir sobremaneira com esse objetivo. 


\subsection{Abordagens Metodológicas para o DeSEnVolvimento das Aulas de}

\section{EDUCAÇÃo FíSICA}

O último elemento que investigamos diz respeito às formas de abordagens que os professores utilizam para o desenvolvimento dos conteúdos ou das temáticas de ensino nas aulas de EF. Conforme os professores mencionaram no tópico anterior, umas das referências de base para o ensino são os PCNs (BRASIL, 1998). De maneira coerente, esses mesmos docentes citaram que desenvolvem suas práticas de ensino a partir das dimensões conceitual, procedimental e atitudinal, perspectiva que, além de constar nos PCNs, também é apontada por Zabala (1998).

Dimensões conceitual (conceitos, características, alguns aspectos técnicos e táticos), procedimental (experimentar das mais diversas práticas da cultura corporal de movimento, tendo em vista mais o para conhecer do que o saber praticar) e atitudinal (reconhecer, criticar e repudiar aspectos negativos das práticas corporais, repudiar violência sob todas as formas, respeitar o outro, valorizar as práticas corporais tendo em vista a promoção de saúde e qualidade de vida) (PROFESSOR IF NORTE 1).

As aulas são organizadas de forma a contemplar as dimensões conceituais, procedimentais e atitudinais. Geralmente partindo da problematização dos temas (verificação do nível de familiaridade dos alunos com os conteúdos) realização das práticas corporais e discussões com os discentes sobre a construção do conhecimento durante o desenvolvimento das aulas (PROFESSOR IF NORDESTE 1).

Dimensões conceituais, procedimentais e atitudinais. Aulas dialogadas e baseadas em posicionamentos dos estudantes sobre cada fenômeno investigado. Tentativa de construção em todas as aulas de pontes entre teoria e prática (PROFESSOR IF SUDESTE 1).

As aulas são teórico-práticas, sendo que os alunos devem dominar tanto o saber fazer como as dimensões conceituais e atitudinais, compreendendo estes elementos da cultura corporal em uma totalidade (PROFESSOR CENTRO-OESTE 1).

Com base nessa concepção, cabe às práticas de ensino proporcionar reflexão sobre fatos, fenômenos, características, conceitos (dimensão conceitual), promover experiências corporais, relacionadas ao saber-fazer (dimensão procedimental) e o desenvolvimento de ações condizentes com a sociedade da qual os estudantes fazem parte (dimensão atitudinal). Além da perspectiva dos saberes conceituais, procedimentais e atitudinais, foram referidas as dimensões dos conteúdos na perspectiva dos saberes corporais (fazer) e saberes conceituais (técnicos e críticos).

Tenho trabalhado em todos os conteúdos com os conhecimentos corporais (fazer) e conceituais (técnicos e críticos). As aulas são teóricas e práticas. Com relação aos conhecimentos críticos, tenho trabalhado com uma temática geral que "transversaliza" todas as práticas corporais estudadas. Abordo esta temática "geral" vinculando as práticas corporais com assuntos crítico-sociais variados, como, por exemplo, violência, consumismo, questões de gênero, meio ambiente, dentre outras. Metodologicamente, além de aulas "mais tradicionais", procuro promover aulas com viés reflexivo através de debates, elaborações teóricas, discussões grupais, pesquisas, seminários, etc. (PROFESSOR IF SUL1). 


\begin{abstract}
As aulas são organizadas e desenvolvidas em Unidades Didáticas. Como critérios de organização dos conhecimentos a serem abordados, adotamos como ponto de apoio os referenciais do RS, divididos em saberes corporais (para saber praticar e para conhecer) e os saberes conceituais (conhecimento técnico e conhecimento crítico). As dimensões dos conteúdos atravessam esses saberes (dimensão conceitual, procedimental e atitudinal) (PROFESSOR IF SUL 2).
\end{abstract}

Percebemos que, teoricamente, os professores apontam formas de abordar a diversidade de práticas corporais com vistas à superação de elementos centrados no fazer corporal. Sobretudo, há apontamentos relacionados à dimensão conceitual dos conteúdos, as quais possuem potencial para proporcionar aos estudantes a compreensão das estruturas que compõem a lógica interna de algumas práticas corporais (GONZÁLEZ; FRAGA, 2012). Além disso, os professores referem elementos de uma "lógica externa", vinculados aos conhecimentos de uma dimensão crítica, ao referir a abordagem de temáticas vinculadas à dimensão social, relacionadas aos conteúdos da EFE.

Nesta perspectiva, ao indicar a realização de estudo, discussão e reflexão, numa abordagem com viés crítico, é oportunizado aos estudantes “desnaturalizar” algumas temáticas. Sob esse entendimento, a reflexão e o diálogo intersubjetivo sobre problemáticas inerentes às práticas corporais (como, por exemplo, o repúdio às formas de violência) podem potencializar uma leitura mais alargada do mundo. Assim, é oportunizado aos estudantes ultrapassarem seus interesses particulares e imediatos, chamando a atenção, por outro lado, de aspectos mais solidários, éticos, estéticos, de respeito, de bem comum, etc., princípios esses que norteiam (ou deveriam nortear) as sociedades democráticas e republicanas.

Chamar a atenção para esse aspecto é bastante importante, pois para Fensterseifer (2013b, p. 145), uma das funções da escola pública é justamente esse, no sentido de "introduzir os alunos no mundo sociocultural que a humanidade construiu, com o objetivo de que possam, com este 'empoderamento', incluir-se no projeto, sempre renovado, da reconstrução do mundo comum”. Esse “empoderamento" podemos considerar como sinônimo do saber, ou seja, do conhecimento que somente as os componentes curriculares podem disponibilizar aos estudantes.

Outros professores mencionaram que tratam pedagogicamente dos conteúdos de ensino a partir de perspectivas que se aproximam em muito de abordagens consideradas críticas para o ensino da EFE (DARIDO, 2003). Essas abordagens de ensino, apesar de obviamente serem oriundas de distintas matrizes epistemológicas, têm como pressuposto básico o estudo de forma crítica sobre as práticas corporais com vistas à emancipação humana. 


\begin{abstract}
Abordagem situada pelo referencial crítico superador, abordando a temática em articulação a temas subjacentes, como a saúde, violência, problemas sociais, cultura,
\end{abstract} etc. (PROFESSOR IF SUL 3).

Utilizo a abordagem crítico emancipatória. Também faço um debate crítico das metodologias (PROFESSOR IF SUDESTE 2).

Trabalho a partir da abordagem Crítico-Superadora e, portanto, da Pedagogia Histórico-Crítica. Parto dos conhecimentos que os alunos já possuem sobre a modalidade, busco desenvolver um pensamento crítico a partir das dimensões histórica, social e econômica que envolvem a modalidade, para que o aluno tenha uma compreensão de totalidade acerca da modalidade estudada e desenvolva autonomia sobre tal (PROFESSOR IF CENTRO-OESTE 2).

As aulas são baseadas em um referencial teórico crítico da Cultura Corporal, nas quais os alunos deverão perceber a dinâmica histórica de cada conteúdo e sua inserção em nossa cultura, as influências político-econômicas que atuam sobre as práticas corporais, e obviamente, o desenvolvimento técnico das habilidades de cada prática corporal para dar condições de prática (PROFESSOR IF CENTRO-OESTE 3).

Via de regra, a compreensão histórico-crítica dos conteúdos é o elemento principal das abordagens, para superação do 'fazer pelo fazer', com vistas ao entendimento de que toda prática corporal foi historicamente produzida pela humanidade e se insere num rol cultural maior (PROFESSOR IF SUL 4).

Os discursos dos professores demonstram uma abordagem holística e histórica acerca das práticas corporais ensinadas nos IFs. Nesse sentido, podemos compreender que a EF e seus respectivos conteúdos de ensino e as temáticas que foram citadas (saúde, violência, problemas sociais), são tratadas pelos professores a partir de uma problematização com o meio sociocultural, com vistas à compreensão crítica das estruturas constitutivas de tal contexto.

A respeito das abordagens citadas pelos docentes, em linhas gerais, podemos entender que as abordagens críticas para o ensino da EF utilizam-se de diferentes vieses teóricos ou bases epistemológicas. De forma resumida, podemos considerar que a concepção Crítico-superadora (SOARES, et al, 2012), apresenta os fundamentos da perspectiva do materialismo históricodialético, enquanto que a perspectiva Crítico-emancipatória (KUNZ, 2004), menciona os pressupostos filosóficos da fenomenologia do movimento e da racionalidade comunicativa. No entanto, no âmbito deste texto, importa que, apesar das divergências em alguns aspectos teóricos, tais abordagens apresentam como pressuposto comum o desenvolvimento do processo da emancipação humana e concebem a EFE como um componente do currículo escolar que possibilita a compreensão histórica em que se desenvolve o movimento humano.

Por fim, a análise permitiu identificar elementos vinculados com perspectivas mais "tradicionais" na abordagem das temáticas do esporte e a promoção da saúde. Destaca-se, em certa medida, avanços pontuais e específicos na abordagem de tais temáticas. Os docentes referiram o seguinte em suas respostas: 
Aulas teóricas e práticas, através de educativos para os fundamentos básicos além de jogos pré-desportivos (PROFESSOR IF NORDESTE 2).

Conhecimento crítico sobre o Esporte e a competição. Aprender as regras básicas dos esportes para saber brincar em qualquer lugar. Saberes Corporais em prol de sua saúde. Vivenciar alguns novos esportes em aulas (PROFESSOR IF NORTE 2).

As modalidades esportivas são abordadas com os conhecimentos técnicos dos fundamentos até o jogo completo. A ginástica é abordada juntamente com as definições teóricas de atividade física e saúde, fazendo uma abordagem crítica ao sedentarismo da população local, disponibilidade de espaços adequados à prática de exercícios físicos, entre outros (PROFESSOR IF CENTRO-OESTE 4).

Trabalho na perspectiva da saúde renovada e utilizo destes conceitos para, também, trabalhar esportes (PROFESSOR IF SUL 5).

Cada prática corporal é organizada para que o aluno conheça as regras básicas, bem como as habilidades e capacidades físicas exigidas para sua dinâmica e assim consiga praticar e conhecer para simples fruição e apropriação de valores sociais, desenvolvimento do pensamento crítico, democrático, autônomo e criativo (PROFESSOR IF SUDESTE 3).

A relação histórica entre a EF, o esporte e a saúde fazem-se presente nas expressões dos professores. Em síntese, os docentes demonstram que a abordagem do esporte é tratada por meio de conhecimentos críticos sobre a competição, aprendizagem de regras básicas, das capacidades físicas e, também, com a prática e aprendizagem de jogos pré-desportivos e de fundamentos técnicos. Apesar de diferentes posicionamentos quanto às metodologias utilizadas para o desenvolvimento das práticas de ensino, percebemos que o esporte ainda é uma importante prática corporal que possibilita diferentes tipos de conhecimentos, como, por exemplos, o conhecimento corporal (capacidades físicas), a aprendizagem sobre aspectos técnicos que possibilitam a fruição e a sua prática e elementos da lógica externa, com a compreensão de aspectos histórico-culturais que condicionam e interferem na constituição do esporte.

Devido a sua importância na sociedade e, principalmente, quanto às possibilidades de aprendizagem que esse fenômeno fornece, reconhecemos a importância de elaborar unidades didáticas a partir de diferentes estratégias metodológicas. Nesse sentido, podemos proporcionar o desenvolvimento de diferentes competências e habilidades para os estudantes, pois aqueles que têm dificuldades em ser proficientes na "prática", terão a oportunidade de expor e aperfeiçoar outras formas de conhecimentos que não esteja vinculado exclusivamente a essa dimensão.

Mesmo referindo elementos que remetem ao desenvolvimento de uma EF mais tradicional (como descrito anteriormente), percebe-se na fala dos docentes, haver movimentos, ainda incipientes, que indicam preocupações educativas para além do ensino da prática esportiva "com um fim em si mesma" ou de uma relação exclusivamente linear (causa e efeito) 
no trato com a temática da saúde. Assim, entendemos que, no contexto do estudo, com as devidas particularidades regionais e institucionais, os professores de $\mathrm{EF}$, em maior ou menor medida, têm buscado o desenvolvimento de processos educativos que se aproximam da ideia descrita por Silva, Silva e Molina Neto (2016, p. 333), para os quais é importante considerar que "[...] a capacidade crítica e a autonomia do estudante a serem desenvolvidas pela Educação Física nos IFes vão além do mero 'exercitar-se', ou de fornecer 'dicas' técnicas sobre como manter o corpo saudável, ou produtivo, ao gosto do mercado de trabalho".

Nessa linha de raciocínio, importa que a EF se configure e se desenvolva em uma perspectiva mais ampla, visando à formação de sujeitos capazes de desmistificar os dogmas, mitos, os preconceitos discriminatórios e demais fenômenos socialmente construídos, por meio de conhecimentos necessários à atuação de forma autônoma e com lucidez em seu cotidiano.

\section{CONCluSÃo}

A pesquisa desenvolvida permitiu compreender melhor como a EFE tem sido desenvolvida nos IFs, especialmente no EMI, no que concerne a três elementos: referenciais (curriculares/teóricos) de base, conteúdos ensinados e suas dimensões, e forma como os conteúdos são abordados pelos professores nas aulas.

Em relação aos referenciais de base para os processos educativos, percebemos que os professores de EF dos IFs desenvolvem suas ações docentes pautadas por três perspectivas bastante importantes e que estão diretamente articuladas. Assim, no contexto deste estudo, há evidências de que os professores articulam os marcos legais e documentos governamentais (BNCC, PCNs, Propostas Curriculares Estaduais, etc.), com os documentos elaborados nas próprias instituições (PPCs), tensionados, neste caso, pelos pressupostos teóricos da área (publicados em diversas obras e por diferentes autores). Esse movimento permite, hipoteticamente e em certa medida, vislumbrar avanços na elaboração de propostas ou projetos educativos para a EFE pautados pela produção de conhecimentos. Além disso, permite ao professor exercer certo protagonismo, pois em vez de "consumir" algo elaborado/proposto por outros, de "fora para dentro", oportuniza a ele (professor), tensionar várias possibilidades e conceber a "sua" EF na instituição, sendo autor de sua própria prática docente.

Essa compreensão pode ser ampliada e melhor fundamentada se tomarmos como pano de fundo a diversidade de conteúdos ensinados e, principalmente, a forma multidimensional com que os conhecimentos são tematizados e produzidos, o que nos permite presumir que alguns paradigmas estabelecidos ao longo da história da área, que a aproximavam de uma 
“atividade" escolar, estão sendo deixados para trás. Do mesmo modo, com base nas abordagens apresentadas pelos docentes, pode-se sugerir que a EF nos IFs vem se configurando como um componente curricular que contribui para a compreensão e/ou reflexão de temas que estão presentes no cotidiano dos sujeitos. Desta forma, com base nas respostas dos docentes acerca dos conteúdos ensinados e das dimensões abordadas para tematização, fica evidente haver uma espécie de "alargamento" do currículo e das práticas corporais ensinadas nos IFs.

Por fim, ao realizar uma espécie de triangulação entre as três perspectivas analisadas neste texto e, principalmente, considerando o alargamento do currículo da EFE nos IFs com as abordagens utilizadas pelos professores, percebe-se um movimento significativo no desenvolvimento da EF sob o prisma de um componente curricular, que produz conhecimentos e saberes multidimensionais, relacionados às práticas corporais. Assim, pode-se dizer que, em certa medida e guardando as particularidades regionais e institucionais, a EF que "se ensina" nos IFs tem dado sua parcela de contribuição para o desenvolvimento de um processo formativo ampliado/alargado, ou em outros termos, contribuindo com a formação dos jovens que estão vinculados à EPT no EMI.

\section{REFERÊNCIAS}

ALMEIDA, Luciano de; FENSTERSEIFER, Paulo Evaldo. Indicativos para pensar uma proposta para a Educação Física escolar: da elaboração ao diálogo com a intervenção. Lúdica pedagógica, v. 1, n. 28, P. 55-67, dez. 2018.

ALMEIDA, Luciano de; MARTINS, Fabrício Döring. Educação Física escolar no ensino médio integrado: limites e possibilidades de uma proposta de intervenção. Revista Prática Docente, Confresa, v. 5, n. 1, p. 100-120, jan/abr 2020.

BAGNARA, Ivan Carlos. The contentes selection in scholl physical education. Fiep Bulletin. Foz do Iguaçu. - Special Edition - Article I. vol. 83, p. 306-311, jan. 2013.

BAGNARA, Ivan Carlos. A interlocução pedagógica na Educação Física escolar: horizontes para pensar a Formação Inicial. 2017. 309 f. Tese (Doutorado em Educação nas Ciências) Universidade Regional do Noroeste do Estado do Rio Grande do Sul, Ijuí, 2017.

\section{BAGNARA, Ivan Carlos; FENSTERSEIFER, Paulo Evaldo. Educação Física Escolar:} política, currículo e didática. Ijuí: Editora Unijuí, 2019.

\section{BARDIN, Laurence. Análise de conteúdo. 6 ed. Lisboa: Edições 70, 2011}

BARROS, André. M; DARIDO, Suraya Cristina. Práticas pedagógicas de dois professores mestres em educação física escolar e o tratamento da dimensão conceitual dos conteúdos. Rev. bras. Educ. Fís. Esporte, São Paulo, v.23, n.1, p. 61-75. 2009. 
BOSCATTO, Juliano, Daniel. Proposta Curricular para a Educação Física no Instituto Federal de Santa Catarina: uma construção colaborativa. 2017. 164f. Tese (Doutorado em Desenvolvimento Humano e Tecnologias. - Universidade Estadual Paulista Júlio de Mesquita Filho - UNESP, Rio Claro, 2017.

BOSCATTO, Juliano, Daniel; DARIDO, Suraya, Cristina. Educação Física no ensino médio integrado à educação Profissional e Tecnológica: Percepções Curriculares. Revista Pensar a Prática, Goiânia: v. 20, n.1, jan. /mar. 2017.

BRACHT, Valter. A educação física escolar no Brasil: o que ela vem sendo e o que pode ser (elementos de uma teoria pedagógica para a educação física). Ijuí: ed. Unijuí, 2019.

BRACHT, Valter et al. Pesquisa em ação: educação física na escola. 3. ed. Ijuí: Unijuí, 2014.

BRASIL. Ministério da Educação. Secretaria de Educação Fundamental. Departamento de Política da Educação Fundamental. Parâmetros Curriculares Nacionais. Brasília, 1998.

BRASIL. Lei número 9394, 20 de dezembro de 1996. Lei de Diretrizes e Bases da Educação Nacional. Câmara dos Deputados. Centro de Documentação e Informação. Brasília, 2017.

BRASIL. Ministério da Educação. Secretaria de Educação Básica. Base Nacional Comum Curricular. Brasília, 2017.

BUOGO, Emara Cristina Bonetti; LARA, Larissa Michelle. Análise da dança como conteúdo estruturante da Educação Física nas diretrizes curriculares da Educação Básica do Paraná.

Rev. Bras. Ciênc. Esporte, Florianópolis, v. 33, n. 4, 2011.

COSTA, Luciane Cristina Arantes; NASCIMENTO, Juarez Vieira. Prática pedagógica de professores de Educação Física: conteúdos e abordagens pedagógicas. R. da Educação Física/UEM, Maringá: v. 17, n. 2, 2006.

DARIDO, Suraya Cristina. Educação física na escola: questões e reflexões. Rio de Janeiro: Guanabara Koogan, 2003.

DINIZ, Irlla Karla; DARIDO, Suraya Cristina. Blog educacional e o ensino das danças folclóricas nas aulas de Educação Física: aproximações a partir do currículo do estado de São Paulo. Movimento, Porto Alegre, v. 21, n. 3. 2015

FENSTERSEIFER, Paulo Evaldo. Formação de professores de Educação Física: uma perspectiva republicana. In: TOMAZETTI, Elisete Medianeira; LOPES, Anemari Roesler Luersen Vieira (Org.). PIBID-UFSM: experiências e aprendizagens. São Leopoldo: Oikos, 2013a. p. 47-60.

FENSTERSEIFER, Paulo Evaldo. Função social da escola pública. In. Anna Rosa Fontella Santiago; Iselda Teresinha Sausen Feil; Lúcia Inês Albrandt (org). O curso de pedagogia da UNIJUI 35 anos. Ijuí, Unijuí, v1. $2013 b$.

GONZÁLEZ, Fernando Jaime; FENSTERSEIFER, Paulo Evaldo. Entre o "não mais" e o “ainda não": pensando saídas do "não-lugar" da EF escolar I. Cadernos de Formação 
RBCE. v. 1, n. 1, p. 9-24, set. 2009a. Disponível em: <revista.cbce.org.br/index.php/cadernos/article/download/929/539>. Acesso em: 15 mar. 2014.

GONZÁLEZ, Fernando Jaime; FENSTERSEIFER, Paulo Evaldo. Entre o "não mais" e o "ainda não": pensando saídas do "não-lugar" da EF escolar II. Cadernos de Formação RBCE. v.1, n. 2, p. 10-21, mar. 2010. Disponível em:

<rbce.cbce.org.br/index.php/cadernos/article/viewFile/978/561>. Acesso em: 15 mar. 2014.

GONZÁLEZ, Fernando Jaime; FRAGA, Alex Branco. Afazeres da Educação Física na escola: planejar, ensinar, partilhar. Erechim: Edelbra, 2012.

GRAMORELLI, Lilian Cristina; NEIRA, Marcos Garcia. Dez anos de parâmetros curriculares nacionais: a prática da Educação Física na visão dos seus autores. Revista Movimento. Porto Alegre, v. 15, n. 04, p. 107-126. 2009.

KUNZ, Elenor. Transformação didático-pedagógica do esporte. 6. ed Ijuí: Unijuí, 2004.

MINAS GERAIS. Secretaria de Estado de Educação de Minas Gerais. Currículo Referência de Minas Gerais. Belo Horizonte, 2018.

PARANÁ. UNCME/PR. SEED/PR. UNDIME/PR. CEE/PR. Referencial Curricular do Paraná. 2018.

PERNAMBUCO. Secretaria de Educação. Parâmetros para a Educação Básica do Estado de Pernambuco: Parâmetros Curriculares de Educação Física Ensino Fundamental e Médio. 2013.

RIO GRANDE DO SUL. Secretaria de Estado da Educação. Departamento Pedagógico (Org.). Referências curriculares do Estado do Rio Grande do Sul: Linguagens, códigos e suas tecnologias: Arte e Educação Física. Porto Alegre: SE/DP, 2009, v. 2, p. 111-181.

RIO GRANDE DO SUL. Referencial Curricular Gaúcho: Linguagens. Porto Alegre. Secretaria de Estado da Educação, Departamento Pedagógico, 2018, v.1.

SACRISTÁN, Gimeno. O currículo: uma reflexão sobre a prática. Tradução Ernani Da Rosa. $3^{\text {a }}$ edição. Porto Alegre: Art Med. 2000.

SILVA, Edna Lucia; MENEZES, Estera Muszkat. Metodologia da pesquisa e elaboração de dissertação. 3. ed. revisada e atualizada. Florianópolis: Laboratório de Ensino à Distância da UFSC, 2001.

SILVA, Eduardo Marczwski. A Educação Física no currículo de Escolas Profissionalizantes da Rede Federal: uma espécie em processo de mutação.Tese (Doutorado em Ciências do Movimento Humano) - Escola de Educação Física, Universidade Federal do Rio Grande do Sul, Porto Alegre, 2014

SILVA, Marlon André; SILVA, Lisandra Oliveira; MOLINA NETO, Vicente. Possibilidades da Educação Física no ensino médio Técnico. Movimento. Porto Alegre, v. 22, n. 1, 2016. 
SOARES, Carmem Lucia, et al. Metodologia do Ensino da Educação Física. 2. ed. $3^{\text {a }}$ reimp. São Paulo: Cortez, 2012. 200 p.

ZABALA, Antoni. A prática educativa: como ensinar. Porto Alegre, Artmed, 1998.

Recebido em: 21 de julho de 2020.

Aprovado em: 14 de dezembro de 2020 . 